\title{
Graduate Student Literature Review: Udder edema in dairy cattle-A possible emerging animal welfare issue*
}

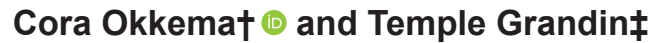

Department of Animal Sciences, Colorado State University, Fort Collins 80523

\begin{abstract}
Physiological udder edema is a noninfectious metabolic disorder in dairy cattle, which may be present in a high percentage of dairy cows. This review summarizes the factors associated with udder edema. They include genetics, nutrition, oxidative stress, and physiological changes in freshening heifers. Udder edema negatively affects the productive life of a dairy cow. Udder support structures may be broken down due to tissue damage. Swollen teats may become sensitive, which makes attaching the milking unit more difficult. The amount of milk produced is decreased due to fluid buildup in the tissue spaces. Risk of secondary diseases, such as mastitis or udder cleft dermatitis, is also increased. All of these elements have an economic impact on the dairy farmer, in both the short term and the long term. If severe, damage could lead to early culling. Some possible methods for managing udder edema include (1) providing a separate diet for late-gestation heifers to monitor anionic salt intake, (2) selecting for either genetic lines with lower milk production or a phenotypic reduction of udder edema, and (3) ensuring that adequate exogenous antioxidants, such as vitamin E, vitamin $\mathrm{C}$, carotenoids, and flavonoids, are provided in the diet to mitigate oxidative stress. In conclusion, udder edema may be an emerging issue that has the potential to seriously affect dairy cow welfare. Many of the research studies are outdated, and research with modern dairy cows is needed. The development of a scientifically validated udder edema scoring system is also needed to assess the severity of udder edema.

Key words: udder edema, heifer, cow, welfare
\end{abstract}

Received July 25, 2020.

Accepted February 8, 2021.

*Submitted to the 2021 ADSA Foundation Graduate Student Literature Review Competition (Production, MS) on February 16, 2021.

†Corresponding author: cora.okkema@colostate.edu

$\ddagger$ Advisor (cheryl.miller@colostate.edu)

\section{INTRODUCTION}

The welfare of a dairy cow has a direct effect on her production ability (von Keyserlingk et al., 2009). Udder edema is common in Holstein dairy operations, with $66 \%$ of cows having udder edema at least once (Morrison et al., 2018). Recent research investigating the welfare of animals with udder edema is sparse. Validated measuring methods for accurately assessing the severity of udder edema are also lacking. This review will cover the information that is currently available. The occurrence of udder edema has increased between the late 1970s and late 1990s (Gröhn et al., 1989; Van Dorp et al., 1998; Morrison et al., 2018). Gröhn et al. (1989) found that $0.004 \%$ (214) of all animals sampled $(61,124)$ were reported to have udder edema. Van Dorp et al. (1998) reported an incidence rate of $0.01 \%$ (1,954 animals) from herds reporting udder edema. Both of these studies were dependent on farms reporting udder edema, which can vary from the actual occurrence rate. Morrison et al. (2018) scored 912 Holstein cows in 3 herds and established prevalence of udder edema based on when edema was present in relation to calving. Edema prepartum affected 12.0\% (109) of animals, edema postpartum affected 10.9\% (99) of animals, and edema prepartum and on at least 1 occasion postpartum affected $47.5 \%$ (433) of animals in the study. Udder edema is the accumulation of lymphatic fluid in and around the interstitial spaces of the mammary gland (Al-Ani, 1984; Kojouri et al., 2015). Physiological edema is not the result of an infectious condition such as mastitis (Moroni et al., 2018). Nevertheless, dairy cattle with udder edema exhibit negative behaviors similar to those observed in mastitis cases, such as decreased lying time, frequent stepping in the parlor (Willis, 1983), and udders and teats that are sensitive to the touch (Vestweber and Al-Ani, 1983). Udder edema can have detrimental effects on the structural integrity of the udder and teats (Moroni et al., 2018), which then increases the risk of mastitis (Slettbakk et al., 1995; Ivemeyer et al., 2011; Morrison et al., 2018) and early culling (Gussmann et al., 2019). The Welfare Quality Assessment Protocol for Cattle (Welfare 
Quality Consortium, 2009) contains no assessment for evaluating the occurrence or severity of swollen udders. Emphasis is placed on injury to the udder and milk SCC. The dairy industry has focused on mastitis, and noninfectious udder disorders may have not received the attention that was needed. A vast majority of research on udder edema is at minimum $30 \mathrm{yr}$ old, adding to the concern that this disorder has been neglected. A need for more research exists. These noninfectious problems have a great potential to impact both a dairy cow's health and wellness and a farm's profit. Edema negatively affects the longevity of the cow and milk production. Determination of the relationship between udder edema and measurable animal-based outcomes and health records will allow producers to promptly detect risk factors and mitigate the negative effects of edema. Some examples of measurable indicators that may be associated with udder edema include swelling severity, udder cleft dermatitis, milk production, early culling, and restless behavior during milking. Udder edema should be investigated as a possible emerging welfare issue in dairy cows.

\section{OVERVIEW OF UDDER EDEMA}

Udder edema is the result of lymphatic fluid accumulating in the interstitial space of the mammary gland and surrounding tissues (Al-Ani, 1984; Tucker et al., 1992; Kojouri et al., 2015; Morrison et al., 2018). In a study on 3 commercial Holstein dairy farms, $30 \%$ of the dairy cows never had udder edema, whereas $48 \%$ had edema both prepartum and postpartum. Furthermore, $12 \%$ had only prepartum edema, whereas $11 \%$ had only postpartum edema (Morrison et al., 2018). Parity is negatively associated with prevalence of edema (Morrison et al., 2018). During pregnancy the increase of fetal pressure in the pelvic area causes blood and lymphatic fluid circulation to be impaired, resulting in fluid buildup in the udder tissues (Al-Ani and Vestweber, 1986). This fluid leads to deterioration of the support structures in the udder (Dentine and McDaniel, 1984), misshapen quarters and teats, increased risk of udder cleft dermatitis, and increased risk of mastitis (Morrison et al., 2018). Tenderness of the udder and malformed teats disrupt milk letdown, increase difficulty of attaching the milking machine due to kicking, and negatively affect production potential throughout an animal's lifetime (Vestweber and Al-Ani, 1983; Melendez et al., 2006; Medrano-Galarza et al., 2012).

Designated as a metabolic disorder (Kojouri et al., 2015), physiologic udder edema has been associated with excessive salt in the diet, greater age at first calving (Malven et al., 1983), above-ideal BCS, genetic traits (Ruegg, 2015), physiological changes during mat- uration and udder development (Dyce and Wensing, 1971; Robbins and Cotran, 1979; Tyler and Ensminger, 2006), oxidative stress (Mueller et al., 1989), increased stress from pen movements when taking out or bringing in new animals to the group, overcrowding (Fustini et al., 2017), and heat stress (Tao and Dahl, 2013). Melendez et al. (2006) found that heifers calving in winter were 3.68 times more likely to develop udder edema than in summer. Sites of fluid accumulation include the brisket, udder, navel, and, in extreme cases, the legs and vulva (Tucker et al., 1992). Edema became less severe and decreased in prevalence as animals increased in parity (Emery et al., 1969; Hayes and Albright, 1976; Morrison et al., 2018). Nevertheless, the presentation of the disorder is the same, causing further damage to the suspensory ligaments and attachments (Vestweber and Al-Ani, 1983). Dairy cows with swollen udders from mastitis exhibit behaviors such as spending less total time lying, less time lying on the affected quarter or quarters, increased standing time, and increased stepping behavior (Siivonen et al., 2011). When milking was performed by the first author, cows with udder edema exhibited greater kicking behavior during milking. Physiological changes such as tenderness of the teats and swelling of udder tissues usually present as painful. Pain has been associated with mastitic udders (Fitzpatrick et al., 2013). The swollen udder tissues caused by edema have not been investigated for painfulness or as a welfare concern on dairy operations.

Pain is one of the pillars in all welfare assessments, along with health, productivity, and the ability to exhibit natural behaviors (von Keyserlingk et al., 2009). Dairy cows with udder edema need to be objectively evaluated for pain. The first author observed that the same cows with udder edema may have tender teats. Milking becomes an unpleasant experience for both human and cow, further resulting in potential injury, infection, or early culling, greatly affecting the profitability and wellbeing of that animal. The purpose of this review is to present the known factors contributing to the development of udder edema. The welfare of a dairy cow may be affected by udder edema.

\section{PHYSIOLOGICAL CHANGES AND MAMMARY DEVELOPMENT}

As a pregnant heifer transitions to the milking string, her body goes through substantial physiological changes. Although the mammary system is already in place, it develops significantly in the last stages of gestation. The animal's internal anatomy begins to change, and, physiologically, the demand of blood for mammary gland development is the precursor to udder edema in primiparous heifers. Mature dairy cows have 
a subcutaneous abdominal vein, also known as the milk vein, whereas, in heifers, this vein is not present. Young cattle have a cranial epigastric vein, which flows anterior to the mammary gland, and a caudal epigastric vein, which flows posterior of the mammary gland. In the latter stages of gestation, a heifer's cranial epigastric and caudal epigastric veins merge through anastomosis, creating the milk vein (Dyce and Wensing, 1971). Figure 1 in Allen et al. (2008) clearly demonstrates the immense vasculature of the mammary gland and how the caudal and cranial mammary veins come together and form the subcutaneous abdominal vein. The creation of the subcutaneous abdominal vein allows for an increase in the amount of blood flow from the mammary gland.

Two types of edema occur: generalized and local (Moroni et al., 2018). Generalized edema can be seen throughout the body. It is most prominent in the ventral areas, such as the barrel, limbs, and udder. Localized edema occurs because of venous stasis, defined as decreased blood flow in the veins due to an increase in capillary pressure, or because of impaired lymphatic drainage (Robbins and Cotran, 1979). Brisket disease (high-altitude disease) is a prime example of localized edema, where fluid collects in a specific anatomic site instead of involving the whole body (Hecht et al., 1962). Due to the increase of blood needed for mammary gland development, the blood flow will reverse in direction. It is exactly the opposite of the blood flow in a young heifer. With this increase in flow, the veins respond by increasing in size (Linzell, 1960). To distribute vital nutrients and oxygen throughout the body, the blood must travel throughout the body to provide proper oxygen, fluid, and nutrient levels to maintain tissues. Two forces that control fluid movement across blood supply membranes are hydrostatic pressure and osmotic pressure. Osmosis is the diffusion of water across a semipermeable membrane to balance out different concentrations of solutes (salt being a primary one) on the 2 sides of the membrane. Osmotic pressure prevents water from moving across the capillary membrane, whereas hydrostatic pressure pulls water across the membrane (Stillwell, 2013). Proteins in blood plasma draw in water from interstitial spaces. When functioning properly, capillaries bring in extravascular fluid to maintain interstitial fluid levels. Without the ability to drain these tissues due to pressure imbalance, fluid builds up in the interstitial tissues, resulting in udder edema. The same result can occur with the obstruction of lymphatic drainage, but this is more localized.

Another important variable in fluid movement is capillary permeability. Udder edema has a "snowball effect," whereby increased blood flow increases hydrostatic pressure (Tyler and Ensminger, 2006). Greater hydrostatic pressure increases capillary permeability, which then causes leaking of fluid into the interstitial tissues. With more blood protein now in the tissues, more fluid will be drawn to the tissue space. As fluid accumulates, the surrounding tissues become inflamed, which obstructs blood and lymph vessels, disrupting fluid movement into and out of the vessels (University of Idaho, 2018). Histamine, a compound released by cells to respond to inflammatory reactions, has a higher concentration in colostrum and plasma in animals with udder edema (Zarkower, 1967). Higher-than-normal histamine concentration in the udder tissue can lead to self-destructive behavior of animals licking the udder tissue and teats until raw, creating significant lesions that can lead to dermatosis (Eyre and Burka, 1978; Yeruham and Markusfeld, 1996). Another study found periparturient udder edema to be associated with increased risk of clinical mastitis (Slettbakk et al., 1995).

With increased blood flow, decreased fluid movement between the tissues and capillaries, and increased histamine levels, these physiological changes present a challenge for dairy farmers. The best approach is prevention before udder edema becomes severe. Due to the natural physiological, metabolic, and vascular functions throughout the last stage of gestation, the farmer needs to manage nutrition, genetic, and calvingin factors such as body condition and age at calving to provide the most optimal scenario to minimize udder edema. Suggestions such as massaging the udder during milking and the use of diuretics have been shown to have some effects of reducing edema (Alhadrami and Faye, 2016).

\section{GENETIC PREDISPOSITION}

Norman et al. (1974) estimated that the genetic correlation of milk yield and edema severity was 0.40 . Van Dorp et al. (1998) state that high-yielding cows have increased genetic potential to develop udder edema, due to the substantial genetic correlation found in their study. Shanks et al. (1978) discovered that cows with high production pedigrees had an $11 \%$ higher incidence of edema compared with those of low production pedigrees. They also found that the most significant difference between levels of severity (mild, moderate, and severe) in udder edema cases was that high production pedigree animals showed greater edema above the rear udder. Need exists to develop validated scoring tools for accurately assessing udder edema. Additionally, $19 \%$ more daughters from high-production sires were diagnosed with udder edema compared with daughters from average sires (Shanks et al., 1978). Increased occurrence is also directly related to increased severity (1-5 score). For detailed score classifications, refer to Table 1 in Dentine and McDaniel (1984). Heritability 
for edema scores in first lactation was estimated at 0.13 by Dentine and McDaniel (1984). Recall that traits lower than 0.15 are considered to have low heritability (Cassell, 2009). Research on genetic influences and udder edema should be conducted with modern heifers and cows of all dairy breeds.

Malven et al. (1983) discovered that as calf birthweight increases edema decreases, but seasonal fluctuations in ambient temperature had no relation to edema. They had also found age at calving $(P<0.01)$ and increased gestation length $(P<0.01)$ to be significantly correlated with presentation of udder edema. Shanks et al. (1978) found no direct effect between age at calving and edema. Research used in support of a direct association between age at calving and increased occurrence of udder edema include Hays and Albright (1966), Malven et al. (1983), Dentine and McDaniel (1983), and Gröhn et al. (1989). The previously stated studies all had a similar conclusion that age at calving has an association with udder edema. Additionally, Nestor et al. (1988) found that primiparous Jersey animals, scored on a scale from 1 to 5 , presented with greater scores of udder edema (3.70) compared with Holstein animals (3.30). It is speculated that edema only appears to be more severe on smaller-framed animals as opposed to taller, wider-framed animals (Wautlet et al., 1990). Melendez et al. (2006) found that for each additional $10 \mathrm{~cm}$ of height at calving, the odds of udder edema increased by $23 \%$. Much of this research dates at least $30 \mathrm{yr}$ from our current time. Therefore, this area must be further investigated for updated information and findings.

Conformation traits of the udder are another area of selection that producers focus on for longevity of the animal and herd uniformity. According to Kuczaj and Blicharski (2008), weak udder ligaments as well as udder and nipple defects were most often observed in cows descended from American bulls (6.2\%). This may be due to the trend of breeding for high production traits in American dairy operations and sire studs. Udder edema causes deterioration of udder support structures, creating low-hanging udders (Dentine and McDaniel, 1984). Lawstuen et al. (1988, p. 796-797) discovered that "The largest phenotypic correlations were for edema and udder depth (0.20) and edema and udder support (0.17). Congestion of udders was phenotypically related to deep, low-hanging udders that lacked cleavage. Also, cows with deep udders were more susceptible to mastitis (0.16)." Kuczaj and Blicharski (2008) concluded that the most common reasons behind forced culling are unfavorable characteristics, including body conformation, udder build-udder support, rump setting-ease of calving, and udder and health status of the animal, specifically fertility and udder and limb disorders. Law- stuen et al. (1988) state that both edema and calving ease had significant and positive estimates of genetic correlation with stature (0.42 and 0.61) and strength, which is how well the body shape supports production and longevity $(0.28$ and 0.85$)$. It must be noted that genetic correlation, how 2 traits influence expression of one another, differs from genetic heritability, the likelihood that a particular trait can be expected to be passed on to the next generation. The reduction of udder edema, with its clear influence on udder support systems and udder health, could potentially have a substantial effect on increasing the longevity of an animal. It may also help reduce early culling due to udder disorders.

\section{PERIPARTURIENT NUTRITION}

The transition period for a dairy cow is a time where the cow's endocrine system prepares the body for parturition and lactogenesis. As a dairy cow shifts from late gestation to early lactation, growth hormone increases and plasma insulin decreases. Acute surges of both hormones occur in plasma concentration at parturition (Kunz et al., 1985). These changes in the endocrine system in conjunction with decreased DMI affect metabolism, leading to mobilization of fat from adipose tissue and glycogen from the liver. The same endocrine system changes and DMI decrease occur in dairy heifers nearing parturition (Rabelo et al., 2003). Hayirli et al. (2003) found that heifer DMI decreased from $1.70 \%$ of $\mathrm{BW}$ at 3 to $1 \mathrm{wk}$ before calving to $1.23 \%$ $\mathrm{BW}$ in the last week. This is significantly different from multiparous cattle in the same stage of lactation, whose DMI decreased from $2.06 \%$ of BW at 3 to 1 wk before calving to $1.36 \% \mathrm{BW}$ in the last week. Additionally, primiparous animals but not mature animals, with an increased CP requirement of 12.7 to $14.7 \%$, have shown improved lactation performance. Silva et al. (2002) found that heifers had reduced mammary development due to rapid BW gain when fed a high-energy diet. Low DMI during the last week of gestation caused impairment of the liver, resulting in decreased lipid and lipoprotein concentrations. This has been suspected as a causative factor in udder edema. Kojouri et al. (2015) found that serum concentrations of total proteins, triglycerides, cholesterol, and lipoproteins were lower in cows with udder edema.

Randall et al. (1974) established that reduction of severity of udder edema can be achieved through salt restriction. Severity was rated on a 5-point scale developed by the researchers. Moore et al. (2000) found that heifers respond differently than mature cows to anionic salts in the feed. Different forms of anionic salts include sodium chloride, magnesium sulfate, calcium sulfate, 
ammonium sulfate, calcium chloride, ammonium chloride, and magnesium chloride. Supplementing with anionic salts into the diet is the only way to achieve a negative DCAD. This is essential to provide the proper dietary needs of a dairy cow. Potassium chloride, which is used as a replacement for sodium chloride, results in the same severity of udder edema as animals supplemented with sodium chloride (Randall et al., 1974). Hutjens (1980) reported that feeding $\mathrm{NaCl}$ (227 g), KCl $(227 \mathrm{~g})$, or both $\mathrm{NaCl}$ and $\mathrm{KCl}(454 \mathrm{~g})$, each day increased the severity of udder edema over that of control cows and heifers fed no $\mathrm{NaCl}$ or $\mathrm{KCl}$. Nestor et al. (1988) stated that animals supplemented with $136 \mathrm{~g}$ of $\mathrm{NaCl}$, $136 \mathrm{~g}$ of $\mathrm{NaCl}$ and $272 \mathrm{~g}$ of $\mathrm{KHCO}_{3}$, or $23 \mathrm{~g}$ of $\mathrm{NaCl}$ and $272 \mathrm{~g}$ of $\mathrm{KHCO}_{3}$, compared with $23 \mathrm{~g}$ of $\mathrm{NaCl}$ with 0 $\mathrm{g}$ of $\mathrm{KHCO}_{3}$ (control), resulted in first-calf heifers having significantly more severe udder edema than control animals $(3.55,3.20,3.51,3.11)$. Severity was measured using a pitting chart developed by Swett et al. (1938). Animals supplemented with these salts also developed edema sooner, and the edema took more time to clear from the udders. Table 1 in Nestor et al. (1988) has a detailed description of the time points at which edema was scored. Lema et al. (1992) found that feeding diets containing $\mathrm{CaCl}_{2}$ to cows during early lactation may extend the beneficial effects of $\mathrm{CaCl}_{2}$ in moderating edema into the early-lactation interval, due to feeding $\mathrm{CaCl}_{2}$ decreasing severity of edema prepartum. Severity was scored on a 10-point scale developed by Tucker et al. (1992). A dietary program adjusting for changes in DMI and protein needs, and including anionic salts, provides complete nutritional requirements for cows during the transition period to decrease the prevalence and severity of udder edema.

\section{OXIDATIVE STRESS}

Oxidative stress occurs when oxygen is not reduced to water during metabolic processes. Partially reduced oxygen becomes a free-radical superoxide $\left(\mathrm{O}^{2-}\right.$; Levine and Kidd, 1985). Increased metabolic rate, rapid growth, high milk production, or extreme aflatoxin exposure could elevate superoxide creation. Superoxide is reduced to hydrogen peroxide $\left(\mathrm{H}_{2} \mathrm{O}_{2}\right)$. Both of these occur naturally during the metabolic process and are not harmful when broken down properly. Damage from these is suspected to be the result of converting into more free radicals and the catalytic transition elements, such as iron, which have harmful effects (Gutteridge and Halliwell, 1994). Release of catalytic Fe becomes more likely under conditions of dietary imbalance, trauma, or stress, often accompanying calving (Madsen, 1990). The body has a normal antioxidant capacity, which is responsible for controlling oxygen radicals through- out the body. Enzymes such as catalase, peroxidase, and superoxide dismutase are involved in free-radical scavenging. Nonenzymatic antioxidants (tocopherols, ascorbic acid, and glutathione) also occur within the body. Exogenous antioxidant molecules, which enter the body through the diet, include vitamin E, vitamin C, carotenoids, and flavonoids (Diplock et al., 1998). When in oxidative stress, reactive oxygen species surpass the defense capability of the antioxidants. Without the control of these radicals by antioxidants and enzymes, free radicals inflict damage on DNA, proteins, and lipids involved in fundamental metabolic processes (Gagné, 2014). These damaged cellular components result in cytotoxicity, genotoxicity, and carcinogenesis when damaged cells proliferate (Gutteridge and Halliwell, 1994). This is a major concern for the stability and functionality of the entire body. Oxidative stress suppresses production of androgens and estrogens, impairing reproduction mechanisms, increasing the occurrence and severity of milk fever, increasing the amount of placental retention, and increasing sodium and water retention, leading to udder edema (Miller et al., 1993). Providing a diet with adequate exogenous antioxidant molecules and amino acids counteracts this disorder (Hou et al., 2015).

Mueller et al. (1989) presented within an abstract the effectiveness of vitamin E, which, as mentioned before, is an antioxidant, in reducing severity of udder edema. It was shown that heifers supplemented with vitamin E (Mueller et al., 1989) and magnesium (Kelly et al., 1990) have less-severe edema. Additionally, Miller et al. (1993) established that daily provision of $1,000 \mathrm{IU}$ of vitamin $\mathrm{E}$ paired with a diet containing at least 0.12 ppm of selenium reduced the severity of udder edema in primiparous cows. In diets having less than $0.06 \mathrm{ppm}$ of selenium, udder edema was not reduced when vitamin E was supplemented (Mueller et al., 1989; Miller et al., 1993). This emphasizes the importance that if 1 or more vitamins or minerals are scarce within the ration, the total system remains impaired. During oxidative stress, animals also have decreased immunity, raising the risk of infections such as mastitis. Eliminating oxidative stress reduces the risk of periparturient disorders, reproductive failure, mastitis, and udder edema. This approach is beneficial for longevity of the udder and the animal as a whole.

\section{UDDER EDEMA AND UDDER CLEFT DERMATITIS}

Udder edema is associated with mastitis and udder cleft dermatitis (Beattie and Taylor, 2000). Both diseases can cause detrimental effects to the animal's welfare, milk production ability, and longevity on the dairy operation. Udder cleft dermatitis (UCD), also 
known as udder rot or necrotic dermatitis, is a skin lesion that appears in areas of tightly adjacent skin. Such areas include the udder cleft along with the medial (inner) aspect of the thigh and the lateral (outer) aspect of the udder (Ruegg, 2015). Friction between these 2 spaces due to a swollen udder or poor confirmation can lead to chafing, dermatitis, and, if persistent enough, necrosis of the tissues. Persson Waller et al. (2014, p. 310) reported that good udder confirmation with "a strong anterior udder attachment was a protective factor." These udder sores present with pus, thickened and inflamed skin, crust, and wounds that easily bleed. A putrid odor has also been noted in advanced cases. Along with udder edema, other risk factors associated with udder cleft dermatitis on a herd level include high yearly milk production, a mean SCC > 200,000 cells/ $\mathrm{mL}$, and an existing prevalence of digital dermatitis (Persson Waller et al., 2014). On an individual cow basis, increasing parity is linked to greater risk of UCD, along with breed, milk production, and previous clinical mastitis cases. Persson Waller et al. (2014) found that animals with UCD had a $3.3 \times$ greater risk for clinical mastitis. It is also suggested that skin lesions, hock lesions, and udder lesions can be a source for Staphylococcus aureus (Capurro et al., 2010). This was the most isolated pathogen by Naqvi et al. (2018) when surveying which pathogens are most prominent in intramammary infections in dairy heifers. Santos et al. (2004) discovered that a reduction in udder edema is linked to a decrease in SCC. Additional studies have shown that udder edema is a risk factor for mastitis (Gröhn et al., 1989; Slettbakk et al., 1995; Waage et al., 2001), which is the most common udder disease in the dairy industry. Slettbakk et al. (1995) and Waage et al. (2001) found cows with teat and udder edema to have an increased risk of clinical mastitis. Waage et al. (2001) also found that udder edema at calving was positively correlated with teat edema, milk leakage 1 wk prepartum, milk leakage at calving, blood in milk at calving, and skin lesions between udder and thigh, which leads to UCD. Slettbakk et al. (1995) state that proposed reasoning for why edema is a risk factor for mastitis is due to edematous udders being more prone to injury and because these udders have impaired blood circulation. Gröhn et al. (1989, p. 1883) also found that "Mastitis diagnoses increased the odds of concurrent or subsequent diagnosis of udder edema, disorder of the abomasum, ketosis, and nonparturient paresis." Melendez et al. (2006) reported that milk yield at the first DHIA test day was $3.6 \mathrm{~kg}$ lower in cows with udder edema. Heise et al. (2016, p. 1253) stated, "Longevity of dairy cows is an economically important trait for farmers and has gained in importance as a global indicator for animal welfare." Heise et al. (2016) further stated, "Longevity results from survival of sequential time periods." Pfeiffer et al. (2015) and Neerhof et al. (2000) found that clinical mastitis does have a negative effect on the longevity of an animal, resulting in early culling. No research has been conducted on the direct impact udder edema has on farm economics. Reduction of udder edema, UCD, and mastitis will not only affect milk production, quality of product, and revenue, they will also increase animals' welfare and longevity potential on the dairy operation.

\section{CONCLUSIONS}

This review addressed multiple factors that contribute to udder edema and secondary risk factors associated with udder edema. Scientifically validated udder edema scoring tools need to be developed. We need to acknowledge the potential of udder edema becoming an emerging welfare issue. Diseases of the udder greatly affect the health and wellness of the cow, the quality and quantity of milk being produced, the condition of the udder ligaments, and the longevity of the animal. Impaired lymphatic drainage and blood circulation results in inflamed tissues and tender teats. Improper or lack of supplementation of protein, anionic salts, and minerals increases the risk for udder edema. Udder edema is also associated with udder cleft dermatitis and increased risk of mastitis. Dermatological lesions on the udder and mammary gland infections are likely to compromise animal welfare. Udder edema can be reduced on a short-term basis by adjusting nutrition and on a long-term basis possibly by shifting genetic selection parameters. The area of udder edema has vast potential for research. New and updated research is needed on udder edema because indicators suggest that it may be an welfare issue. The second reason for new research is that most cited material is old and needs updating, including current prevalence of udder edema. Research is needed to fully evaluate the prevalence of this disorder across the industry.

\section{ACKNOWLEDGMENTS}

The authors have not stated any conflicts of interest.

\section{REFERENCES}

Al-Ani, F., and J. G. E. Vestweber. 1986. Udder edema: An updated review. Vet. Bull. 56:763-769.

Al-Ani, F. K. A.-R. 1984. Udder Edema in Cattle. Kansas State University.

Alhadrami, G. A., and B. Faye. 2016. Animals that produce dairy foods: Camel. Reference Module in Food Science. Elsevier. https:/ /doi.org/10.1016/B978-0-08-100596-5.00620-X.

Allen, A. J., G. M. Barrington, and S. M. Parish. 2008. Physiologic mastectomy via flank laparotomy. Vet. Clin. North Am. Food 
Anim. Pract. 24:511-516. https://doi.org/10.1016/j.cvfa.2008.06 .006 .

Beattie, K. G., and D. J. Taylor. 2000. An investigation into intertrigo (necrotic dermatitis or 'foul udder') in dairy cows. Cattle Pract. 8:377-380.

Capurro, A., A. Aspan, H. Ericsson Unnerstad, K. Persson Waller, and K. Artursson. 2010. Identification of potential sources of Staphylococcus aureus in herds with mastitis problems. J. Dairy Sci. 93:180-191. https://doi.org/10.3168/jds.2009-2471.

Cassell, B. 2009. Using Heritability for Genetic Improvement. VCE Publications.

Dentine, M. R., and B. T. McDaniel. 1983. Variation of edema scores from herd-year, age, calving month, and sire. J. Dairy Sci. 66:23912399. https://doi.org/10.3168/jds.S0022-0302(83)82097-9.

Dentine, M. R., and B. T. McDaniel. 1984. Associations of subjective udder edema scores and descriptive trait codes for udder types. J. Dairy Sci. 67:208-215. https://doi.org/10.3168/jds.S0022 -0302(84)81286-2.

Diplock, A. T., J. L. Charuleux, G. Crozier-Willi, F. J. Kok, C. RiceEvans, M. Roberfroid, W. Stahl, and J. Vina-Ribes. 1998. Functional food science and defence against reactive oxidative species. Br. J. Nutr. 80(Suppl. 1):S77-S112. https://doi.org/10.1079/ BJN19980106.

Dyce, K. M., and C. T. G. Wensing. 1971. Essentials of Bovine Anatomy. Lea and Febiger.

Emery, R. S., H. D. Hafs, D. Armstrong, and W. W. Snyder. 1969. Prepartum grain feeding effects on milk production, mammary edema, and incidence of diseases. J. Dairy Sci. 52:345-351. https:/ /doi.org/10.3168/jds.S0022-0302(69)86559-8.

Eyre, P., and J. F. Burka. 1978. Hypersensitivity in cattle and sheep: A pharmacological review. J. Vet. Pharmacol. Ther. 1:97-109. https://doi.org/10.1111/j.1365-2885.1978.tb00313.x.

Fitzpatrick, C. E., N. Chapinal, C. S. Petersson-Wolfe, T. J. DeVries, D. F. Kelton, T. F. Duffield, and K. E. Leslie. 2013. The effect of meloxicam on pain sensitivity, rumination time, and clinical signs in dairy cows with endotoxin-induced clinical mastitis. J. Dairy Sci. 96:2847-2856. https://doi.org/10.3168/jds.2012-5855.

Fustini, M., G. Galeati, G. Gabai, L. E. Mammi, D. Bucci, M. Baratta, P. A. Accorsi, and A. Formigoni. 2017. Overstocking dairy cows during the dry period affects dehydroepiandrosterone and cortisol secretion. J. Dairy Sci. 100:620-628. https://doi.org/10.3168/jds .2016-11293.

Gagné, F. 2014. Oxidative stress. Pages 103-115 in Biochemical Ecotoxicology. Elsevier.

Gröhn, Y. T., H. N. Erb, C. E. McCulloch, and H. S. Saloniemi. 1989. Epidemiology of metabolic disorders in dairy cattle: Association among host characteristics, disease, and production. J. Dairy Sci. 72:1876-1885. https://doi.org/10.3168/jds.S0022-0302(89)79306 $-1$.

Gussmann, M., M. Denwood, C. Kirkeby, M. Farre, and T. Halasa. 2019. Associations between udder health and culling in dairy cows. Prev. Vet. Med. 171:104751. https://doi.org/10.1016/j.prevetmed .2019.104751.

Gutteridge, J. M. C., and B. Halliwell. 1994. Antioxidants in Nutrition, Health, and Disease. Oxford University Press.

Hayes, R. L., and J. L. Albright. 1976. Older heifers have mere severe edema. Hoard's Dairyman 75:1178. January 25, 1976.

Hayirli, A., R. R. Grummer, E. V. Nordheim, and P. M. Crump. 2003. Models for predicting dry matter intake of Holsteins during the prefresh transition period. J. Dairy Sci. 86:1771-1779. https://doi .org/10.3168/jds.S0022-0302(03)73762-X.

Hays, R. L., and L. Albright. 1966. Udder edema: Its incidence and severity as affected by certain management practices. Ill. Res. 8:6.

Hecht, H. H., H. Kuida, R. L. Lange, J. L. Thorne, and A. M. Brown. 1962. Brisket disease. III. Clinical features and hemodynamic observations in altitude-dependent right heart failure of cattle. Am. J. Med. 32:171-183. https://doi.org/10.1016/0002-9343(62)90288 -7 .

Heise, J., Z. Liu, K. F. Stock, S. Rensing, F. Reinhardt, and H. Simianer. 2016. The genetic structure of longevity in dairy cows. J. Dairy Sci. 99:1253-1265. https://doi.org/10.3168/jds.2015-10163.
Hou, R., C. Jiang, Q. Zheng, C. Wang, and J. R. Xu. 2015. The AreA transcription factor mediates the regulation of deoxynivalenol (DON) synthesis by ammonium and cyclic adenosine monophosphate (cAMP) signaling in Fusarium graminearum. Mol. Plant Pathol. 16:987-999. https://doi.org/10.1111/mpp.12254.

Hutjens, M. F. 1980. Can we feed to prevent udder edema? Hoard's Dairyman 125:1178.

Ivemeyer, S., U. Knierim, and S. Waiblinger. 2011. Effect of humananimal relationship and management on udder health in Swiss dairy herds. J. Dairy Sci. 94:5890-5902. https://doi.org/10.3168/ jds.2010-4048.

Kelly, F. M., J. K. Bernard, J. K. Miller, and F. J. Mueller. 1990. Influence of vitamin $\mathrm{E}$ and magnesium supplementation on udder edema in primigravid Holstein heifers. J. Dairy Sci. 73:166 (Abstract).

Kojouri, G. A., M. Mosavi Pouryeganeh, S. Nekouei, and S. Nazifi. 2015. Udder edema and association with some serum biochemical measurands and dietary factors in first calving cows. Iran. J. Vet. Res. 16:345-349.

Kuczaj, M. Z. A., and P. Blicharski. 2008. Reasons for the culling of Polish Holstein-Friesian cows in a high yield herd. Med. Welt 64:1205-1208.

Kunz, P. L., J. W. Blum, I. C. Hart, H. Bickel, and J. Landis. 1985. Effects of different energy intakes before and after calving on food intake, performance and blood hormones and metabolites in dairy cows. Anim. Sci. 40:219-231. https://doi.org/10.1017/ S0003356100025320.

Lawstuen, D. A., L. B. Hansen, G. R. Steuernagel, and L. P. Johnson. 1988. Management traits scored linearly by dairy producers. J. Dairy Sci. 71:788-799. https://doi.org/10.3168/jds.S0022 $-0302(88) 79619-8$.

Lema, M., W. B. Tucker, M. Aslam, I. S. Shin, P. Le Ruyet, and G. D. Adams. 1992. Influence of calcium chloride fed prepartum on severity of edema and lactational performance of dairy heifers. J. Dairy Sci. 75:2388-2393. https://doi.org/10.3168/jds.S0022 -0302(92)78000-X.

Levine, S. A., and P. M. Kidd. 1985. Antioxidant Adaptation: Its Role in Free Radical Pathology. Allergy Research Group.

Linzell, J. L. 1960. Valvular incompetence in the venous drainage of the udder. J. Physiol. 153:481-491. https://doi.org/10.1113/ jphysiol.1960.sp006549.

Madsen, F. C. 1990. Effect of disease on the metabolism of essential trace elements: A role for dietary coordination complexes. Feed Manage. 41:20.

Malven, P. V., R. E. Erb, M. F. D'Amico, T. S. Stewart, and B. P. Chew. 1983. Factors associated with edema of the mammary gland in primigravid dairy heifers. J. Dairy Sci. 66:246-252. https://doi .org/10.3168/jds.S0022-0302(83)81783-4.

Medrano-Galarza, C., J. Gibbons, S. Wagner, A. M. de Passille, and J. Rushen. 2012. Behavioral changes in dairy cows with mastitis. J. Dairy Sci. 95:6994-7002. https://doi.org/10.3168/jds.2011-5247.

Melendez, P., C. C. Hofer, and G. A. Donovan. 2006. Risk factors for udder edema and its association with lactation performance on primiparous Holstein cows in a large Florida herd, U.S.A. Prev. Vet. Med. 76:211-221. https://doi.org/10.1016/j.prevetmed.2006 .05 .004 .

Miller, J. K., E. Brzezinska-Slebodzinska, and F. C. Madsen. 1993. Oxidative stress, antioxidants, and animal function. J. Dairy Sci. 76:2812-2823. https://doi.org/10.3168/jds.S0022-0302(93)77620 $-1$.

Moore, S. J., M. J. VandeHaar, B. K. Sharma, T. E. Pilbeam, D. K. Beede, H. F. Bucholtz, J. S. Liesman, R. L. Horst, and J. P. Goff. 2000. Effects of altering dietary cation-anion difference on calcium and energy metabolism in peripartum cows. J. Dairy Sci. 83:20952104. https://doi.org/10.3168/jds.S0022-0302(00)75091-0.

Moroni, P., D. V. Nydam, P. A. Ospina, J. C. Scillieri-Smith, P. D. Virkler, R. D. Watters, F. L. Welcome, M. J. Zurakowski, N. G. Ducharme, and A. E. Yeager. 2018. Diseases of the teats and udder. Pages 389-465 in Rebhun's Diseases of Dairy Cattle. 3rd ed. S. F. Peek and T. J. Divers. Elsevier. 
Morrison, E. I., T. J. DeVries, and S. J. LeBlanc. 2018. Short communication: Associations of udder edema with health, milk yield, and reproduction in dairy cows in early lactation. J. Dairy Sci. 101:9521-9526. https://doi.org/10.3168/jds.2018-14539.

Mueller, F. J., J. K. Miller, N. Ramsey, R. C. DeLost, and F. C. Madsen. 1989. Reduced udder edema in heifers fed vitamin E prepartum. J. Dairy Sci. 72:2211 (Abstr.).

Naqvi, S. A., J. De Buck, S. Dufour, and H. W. Barkema. 2018. Udder health in Canadian dairy heifers during early lactation. J. Dairy Sci. 101:3233-3247. https://doi.org/10.3168/jds.2017-13579.

Neerhof, H. J., P. Madsen, C. P. Ducrocq, A. R. Vollema, J. Jensen, and I. R. Korsgaard. 2000. Relationships between mastitis and functional longevity in Danish Black and White dairy cattle estimated using survival analysis. J. Dairy Sci. 83:1064-1071. https:/ /doi.org/10.3168/jds.S0022-0302(00)74970-8.

Nestor, K. E. Jr., R. W. Hemken, and R. J. Harmon. 1988. Influence of sodium chloride and potassium bicarbonate on udder edema and selected blood parameters. J. Dairy Sci. 71:366-372. https://doi .org/10.3168/jds.S0022-0302(88)79565-X.

Norman, H. D., R. L. Powell, and L. D. Van Vleck. 1974. Genetic relationships among dairy cattle type appraisal traits and milk yield. J. Dairy Sci. 57(Suppl. 1):647 (Abstr.).

Persson Waller, K., M. Bengtsson, and A. K. Nyman. 2014. Prevalence and risk factors for udder cleft dermatitis in dairy cattle. J. Dairy Sci. 97:310-318. https://doi.org/10.3168/jds.2013-7186.

Pfeiffer, C., C. Fuerst, V. Ducrocq, and B. Fuerst-Waltl. 2015. Short communication: Genetic relationships between functional longevity and direct health traits in Austrian Fleckvieh cattle. J. Dairy Sci. 98:7380-7383. https://doi.org/10.3168/jds.2015-9632.

Rabelo, E., R. L. Rezende, S. J. Bertics, and R. R. Grummer. 2003. Effects of transition diets varying in dietary energy density on lactation performance and ruminal parameters of dairy cows. J. Dairy Sci. 86:916-925. https://doi.org/10.3168/jds.S0022-0302(03)73674 -1 .

Randall, W. E., R. W. Hemken, L. S. Bull, and L. W. Douglas. 1974. Effect of dietary sodium and potassium on udder edema in Holstein heifers. J. Dairy Sci. 57:472-475. https://doi.org/10.3168/jds .S0022-0302(74)84916-7.

Robbins, S. L., and R. S. Cotran. 1979. Pathologic Basis of Disease. W. B. Saunders Co.

Ruegg, P. L. 2015. Diseases of Bovine Teat and Skin. Accessed Mar. 7, 2020. https://www.merckvetmanual.com/reproductive-system/ udder-diseases /diseases-of-bovine-teats-and-skin.

Santos, J. E. P., R. L. A. Cerri, J. H. Kirk, S. O. Juchem, and M. Villaseňor. 2004. Effect of prepartum milking of primigravid cows on mammary gland health and lactation performance. Livest. Prod. Sci. 86:105-116. https://doi.org/10.1016/S0301-6226(03)00149-0.

Shanks, R. D., A. E. Freeman, P. J. Berger, and D. H. Kelley. 1978. Effect of selection for milk production and general health of the dairy cow. J. Dairy Sci. 61:1765-1772. https://doi.org/10.3168/jds .S0022-0302(78)83800-4.

Siivonen, J., S. Taponen, M. Hovinen, M. Pastell, B. J. Lensink, S. Pyörälä, and L. Hänninen. 2011. Impact of acute clinical mastitis on cow behaviour. Appl. Anim. Behav. Sci. 132:101-106. https:// doi.org/10.1016/j.applanim.2011.04.005.

Silva, L. F. P., M. J. VandeHaar, B. K. Whitlock, R. P. N. Radcliff, and H. A. Tucker. 2002. Short Communication: Relationship between body growth and mammary development in dairy heifers. J. Dairy Sci. 85:2600-2602. https://doi.org/10.3168/jds.S0022 -0302(02) 74344-0.
Slettbakk, T., A. Jorstad, T. B. Farver, and J. C. Holmes. 1995. Impact of milking characteristics and morphology of udder and teats on clinical mastitis in first and second lactation Norwegian cattle. Prev. Vet. Med. 24:235-244. https://doi.org/10.1016/0167 $-5877(95) 00490-\mathrm{N}$.

Stillwell, W. 2013. An Introduction to Biological Membranes. 2nd ed. Elsevier.

Swett, W. W., C. A. Matthews, and R. R. Graves. 1938. Nature of swelling in the udder of a cow at calving time. J. Dairy Sci. 21:713723. https://doi.org/10.3168/jds.S0022-0302(38)93026-7.

Tao, S., and G. E. Dahl. 2013. Invited review: Heat stress effects during late gestation on dry cows and their calves. J. Dairy Sci. 96:4079-4093. https://doi.org/10.3168/jds.2012-6278.

Tucker, W. B., G. D. Adams, M. Lema, M. Aslam, S. Shin, P. Le Ruyet, and D. L. Weeks. 1992. Evaluation of a system for rating edema in dairy cattle. J. Dairy Sci. 75:2382-2387. https://doi.org/ 10.3168/jds.S0022-0302(92)77999-5.

Tyler, H. D., and M. E. Ensminger. 2006. Dairy Cattle Science. 4th ed. Pearson Prentice Hall.

University of Idaho. 2018. Anatomy and Lactation Physiology. Accessed Apr. 9, 2020. https://www.webpages.uidaho.edu/avs472/ Word/Mastitis\%20and\%20Milking/Mammary\%20Udder\%201\%20 [Compatibility\%20Mode].pdf.

Van Dorp, T. E., J. C. Dekkers, S. W. Martin, and J. P. Noordhuizen. 1998. Genetic parameters of health disorders, and relationships with 305-day milk yield and conformation traits of registered Holstein cows. J. Dairy Sci. 81:2264-2270. https://doi.org/10.3168/ jds.S0022-0302(98)75806-0.

Vestweber, J. G., and F. K. Al-Ani. 1983. Udder edema in cattle. Pages 5-12 in Proc. Compend. Contin. Educ. Pract. Vet.

von Keyserlingk, M. A., J. Rushen, A. M. de Passille, and D. M. Weary. 2009. Invited review: The welfare of dairy cattle-Key concepts and the role of science. J. Dairy Sci. 92:4101-4111. https:// doi.org/10.3168/jds.2009-2326.

Waage, S., S. A. Odegaard, A. Lund, S. Brattgjerd, and T. Rothe. 2001. Case-control study of risk factors for clinical mastitis in postpartum dairy heifers. J. Dairy Sci. 84:392-399. https://doi.org/10 .3168/jds.S0022-0302(01)74489-X.

Wautlet, R. G., L. B. Hansen, C. W. Young, H. Chester-Jones, and G. D. Marx. 1990. Calving disorders of primiparous Holsteins from designed selection studies. J. Dairy Sci. 73:2555-2562. https://doi .org/10.3168/jds.S0022-0302(90)78941-2.

Welfare Quality Consortium. 2009. Welfare Quality Assessment Protocol for Cattle. Welfare Quality Consortium.

Willis, G. L. 1983. A possible relationship between the flinch, step and kick response and milk yield in lactating cows. Appl. Anim. Ethol. 10:287-290. https://doi.org/10.1016/0304-3762(83)90179-7.

Yeruham, I., and O. Markusfeld. 1996. Self-destructive behaviour in dairy cattle. Vet. Rec. 138:308. https://doi.org/10.1136/vr.138.13 .308 .

Zarkower, A. 1967. Histamine in the cow: Pre- and postparturition histamine concentrations in plasma, milk, and tissue. Am. J. Vet. Res. 28:1751-1755.

\section{ORCIDS}

Cora Okkema @ https://orcid.org/0000-0001-9572-982X 